\title{
Non-Sterile Vibratory Powder Filling Method
}

National Cancer Institute

\section{Source}

National Cancer Institute. Non-Sterile Vibratory Powder Filling Method. NCI Thesaurus.

Code C112996.

A process that fills a dosage unit using a vibrating perforated plate to deliver a powder, which is not performed under sterile conditions. 